\section{(6) OPEN ACCESS}

\title{
Effects of a transitional palliative care model on patients with end-stage heart failure: a randomised controlled trial
}

\author{
Frances Kam Yuet Wong, ${ }^{1}$ Alina Yee Man Ng, ${ }_{1}$ Paul Hong Lee, ${ }^{1}$ Po-tin Lam, \\ Jeffrey Sheung Ching $\mathrm{Ng}^{3}$ Nancy Hiu Yim Ng, ${ }^{2}$ Michael Mau Kwong Sham ${ }^{4}$
}

\begin{abstract}
- Additional material is published online only. To view please visit the journal online (http://dx.doi.org/10.1136/ heartjnl-2015-308638).

${ }^{1}$ School of Nursing, The Hong Kong Polytechnic University, Hong Kong, China

${ }^{2}$ Department of Medicine and Geriatrics, United Christian Hospital, Hong Kong, China ${ }^{3}$ Department of Medicine, Haven of Hope Hospital, Hong Kong, China

${ }^{4}$ Palliative Medical Unit, Grantham Hospital, Hong Kong, China
\end{abstract}

\section{Correspondence to} Professor Frances Kam Yuet Wong, School of Nursing, The Hong Kong Polytechnic University, Hung Hom, Kowloon, Hong Kong, China; frances.wong@polyu.edu.hk

Received 2 September 2015 Revised 10 February 2016 Accepted 18 February 2016 Published Online First 11 March 2016

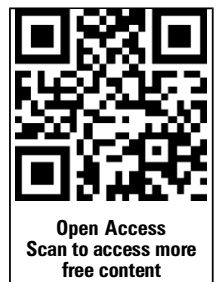

\section{SLinked}

- http://dx.doi.org/10.1136/ heartjnl-2016-309385

To cite: Wong FKY, $\mathrm{Ng}$ AYM, Lee PH, et al. Heart 2016;102:

1100-1108.

\section{ABSTRACT}

Objective To examine the effects of home-based transitional palliative care for patients with end-stage heart failure (ESHF) after hospital discharge.

Methods This was a randomised controlled trial conducted in three hospitals in Hong Kong. The recruited subjects were patients with ESHF who had been discharged home from hospitals and referred for palliative service, and who met the specified inclusion criteria. The interventions consisted of weekly home visits/telephone calls in the first 4 weeks then monthly follow-up, provided by a nurse case manager supported by a multidisciplinary team. The primary outcome measures were any readmission and count of readmissions within 4 and 12 weeks after index discharge, compared using $\chi^{2}$ tests and Poisson regression, respectively. Secondarily, change in symptoms over time between control and intervention groups were evaluated using generalised estimating equation analyses of data collected using the Edmonton Symptom Assessment Scale (ESAS).

Results The intervention group $(n=43)$ had a significantly lower readmission rate than the control group $(n=41)$ at 12 weeks (intervention $33.6 \%$ vs control $61.0 \% \chi^{2}=6.8, p=0.009$ ). The mean number (SE) of readmissions for the intervention and control groups was, respectively, $0.42(0.10)$ and $1.10(0.16)$ and the difference was significant $(p=0.001)$. The relative risk $(\mathrm{Cl})$ for 12 -week readmissions for the intervention group was 0.55 (0.35 to 0.88). There was no significant difference in readmissions between groups at 4 weeks. However, when compared with the control group, the intervention group experienced significantly higher clinical improvement in depression $(45.9 \%$ vs $16.1 \%, p<0.05)$, dyspnoea (62.2\% vs $29.0 \%, p<0.05$ ) and total ESAS score $(73.0 \%$ vs $41.4 \%, p<0.05)$ at 4 weeks. There were significant differences between groups in changes over time in quality of life (QOL) measured by McGill QOL $(p<0.05)$ and chronic HF $(p<0.01)$ questionnaires.

Conclusions This study provides evidence of the effectiveness of a postdischarge transitional care palliative programme in reducing readmissions and improving symptom control among patients with ESHF. Trial registration number HKCTR-1562; Results.

\section{INTRODUCTION}

Heart failure (HF) is a worldwide health issue $e^{12}$ resulting in high mortality rates of $40 \%$ and $75 \%$, respectively, within the first year ${ }^{3}$ and at 5 years ${ }^{4}$ after diagnosis. The treatment of chronic HF has improved in the last decade, with updated national guidelines for diagnosis and disease management. Palliative care (PC) can be initiated when end-stage $\mathrm{HF}$ (ESHF) is diagnosed, ${ }^{1}{ }^{2}$ with the ratio of PC to life-prolonging care gradually increasing when patients are refractory to treatment. ${ }^{15}$

Patients with advanced HF experience marked reductions in health-related quality of life (QOL). The three most prevalent physical symptoms reported by these patients are fatigue, dyspnoea and swelling of arms and legs. ${ }^{3}$ Psychologically, patients with HF experience feelings of uncertainty and fear since their conditions can change rapidly and the feeling of death is imminent. ${ }^{6}$ Socially, patients with $\mathrm{HF}$ feel isolated and lonely, ${ }^{6}$ and regard themselves as a burden to their carers since they often require assistance in daily living. ${ }^{7}$ These patients, with complicated issues in refractory symptoms, psychological distress and difficult decision-making involving families, would benefit from a specialist PC team trained in these skills. ${ }^{8}$ However, PC is reported to be underused among patients with $\mathrm{HF}^{9}{ }^{10}$

The reasons for low use of PC among patients with ESHF are multifactorial, disease-related, person-related and system-related. ${ }^{4}$ The unpredictable disease trajectories in HF make the prognostication of life span difficult. ${ }^{11}$ Care providers, including cardiologists and primary care physicians, lack appreciation of the palliative concept and fail to recognise specialist PC as a tangible service. ${ }^{12}$ Patients are often unaware of PC as a treatment choice. ${ }^{2}$ At the system level, there is a lack of care coordination in the specialties of $\mathrm{HF}$ and $\mathrm{PC}^{4}$ which may be attributed to suboptimal trust and rapport between providers. ${ }^{12}$ There need to be clearer guidelines of how and when specialist PC should be integrated into advanced $\mathrm{HF}$ management. $^{12}$

PC has a long history among patients with cancer. In the last decade, studies have emerged using non-cancer and cancer patients as a study population when testing the effects of PC models. One of the earlier studies was conducted by Brumley et al, who tested an in-home PC multidisciplinary intervention programme among patients with cancer, chronic obstructive pulmonary disease (COPD) and chronic heart failure (CHF), finding significant reductions in emergency room visits, hospital days and costs compared with a usual care 
group. ${ }^{11}$ A systematic review that examined studies involving both cancer and non-cancer patients also showed that multidisciplinary PC support can significantly reduce readmissions, with particularly strong evidence among the HF group. ${ }^{13}$

The models for current provision of PC for patients with HF vary, with some hospital-based and others community-based. ${ }^{14}$ A current review showed that home-based PC interventions among community HF subjects could reduce hospital admissions and enhance symptom management. ${ }^{15}$ Another study, testing the effects of clinic-based consultations, found that the ability of patients with HF in symptom management was better with more frequent clinic consultations. ${ }^{16}$ There is a lack of studies exploring the effects of transitional care support for patients with ESHF. Transitional care involves deliberately designed programmes to provide proactive and continuous support to patients returning home after hospital discharge with the intensity and duration of activity events planned with evidence support. Previous studies have demonstrated the effects of transitional care programmes among medical patients in reducing hospital readmissions. ${ }^{17} 18$ There is no previous transitional programme designed for patients with ESHF and thus no empirical results reporting its effects. The objective of this study was to examine the effects of home-based transitional PC for patients with ESHF after hospital discharge.

\section{METHODS}

\section{Study design}

This was a multiple-site randomised controlled trial involving two arms. The intervention group received home visits/telephone calls every week for the first month and less frequently during the subsequent months for a total of 12 months. This study will report results of readmissions up to 12 weeks and other outcomes up to 4 weeks, the initial endpoint after delivery of the intensive intervention. Both groups received usual care, which consisted of PC medical clinic consultation, discharge advice on symptom management and medication and referrals if appropriate (eg, home visits).

\section{Setting and subjects}

The study took place in three hospitals within the Hospital Authority (HA), Hong Kong between May 2013 and December 2014. The HA is government funded and employs corporate governance which aligns practice within the system. These three hospitals were selected because there were established referral systems between the medical/cardiac and PC teams. Subjects who fulfilled the following criteria were recruited: (a) met two of the following indicators identified as ESHF by the Prognostic Indicator Guidance: ${ }^{19}$ (i) CHF New York Heart Association (NYHA) stage III or IV, (ii) patient thought to be in the last year of life by clinicians, (iii) repeated hospital admissions (three within 1 year) with symptoms of HF and (iv) existence of physical/psychological symptoms despite optimal tolerated therapy; (b) Cantonese-speaking; (c) living within the service area; (d) contactable by phone and (e) referral accepted by PC team. The exclusion criteria were: (a) discharged to institutions, (b) inability to communicate, (c) diagnosed with severe psychiatric disorders and (d) recruited to other programmes. An advanced practice nurse (APN) helped to screen cases for eligibility (see online supplementary material) and confirmed the recruitment with the physician. The patients were approached, and consenting subjects signed a consent form. The responsible APN then called the site investigator for a random assignment generated by the computer software Research Randomizer. The investigator, who had no knowledge of the subject's identity, provided the assignment based on sequential computer numbers (' 1 '= control; ' 2 '= study).

We assumed the effect of our study to be similar to that of a previous study that used home-based palliative follow-up for patients with end-stage organ failure. ${ }^{20}$ In that study, the average number of 30-day readmissions was reduced from 2.23 to 1.25 . By Lehr's equation, ${ }^{21}$ a sample size of 29 per group $\left(=4 /\left(2.23^{0.5}-1.25^{0.5}\right)^{2}\right)$ is adequate to achieve $80 \%$ power with a significance level of 0.05 . Taking into account a $20 \%$ dropout rate, 35 subjects were needed per group.

\section{Intervention}

The design of the Transitional Care Palliative-ESHF (TCP-ESHF) programme was based on two main conceptual guides: the recommended principles of PC for patients with $\mathrm{HF}$ and the 4Cs for transitional care model. For the principles of PC, the team referenced composite guidelines drawn from Scotland, Europe and Canada, ${ }^{5} 22$ which could be summarised into the following six principles: (i) case management with periodic review; (ii) discussion of end-of-life issues; (iii) multidisciplinary approach; (iv) staff development for communication, cardiovascular and PC; (v) discussion of treatment preferences and (vi) integrated model of care. The transitional care framework was the 4Cs model tested and used by Wong et al with general medical patients. ${ }^{17} 18$ The 4Cs are comprehensiveness, continuity, coordination and collaboration in alignment with the PC principles mentioned above in providing continuous and coordinated care with multidisciplinary support. Previous studies ${ }^{17} 18$ have shown that a 4-week intervention with weekly structured events provided a strong enough dose to bring about effects.

The TCP-ESHF was delivered by nurse case managers (NCMs) who were qualified PC home nurses with experience of caring for patients with HF. The NCMs were supported by the PC physician in service delivery. Before a patient's discharge, the nurse met the patient/patient's family to conduct a predischarge assessment. After discharge, the patient was followed up in the first 4 weeks as below:

Week 1-the NCM and trained volunteers (TVs) conducted a home visit together.

Week 2-the NCM provided a telephone follow-up.

Week 3-the TVs conducted a home visit in pairs.

Week 4-the NCM provided a telephone follow-up.

After the first 4 weeks, the subjects in the intervention group received monthly home visits and telephone follow-up until the end of 12 weeks. Based on the Omaha framework, ${ }^{17}$ the NCM assessed patients' needs in the environmental, psychosocial, physiological and health-related behaviour domains and intervened accordingly. The Omaha system was first developed in the USA and has been tested and used locally. ${ }^{17}{ }^{18}$ At each of the encounters, the NCM would set goals and develop a mutually agreed care plan with the patients. The home visits, telephone calls and referrals were governed by protocols to ensure a consistent approach to care delivery. The NCM was assisted by TVs who were nursing students trained in providing patient support. ${ }^{17} 18$ The NCMs and TVs received 18 and $9 \mathrm{~h}$ of training, respectively (see online supplementary material).

\section{Placebo calls for the control group}

The control group received two attention control social calls ${ }^{17} 18$ from an assistant, consisting of light conversation topics unrelated to clinical issues. 


\section{Data collection and measures}

Data were collected at discharge (O1), at the primary endpoint at 4 weeks postdischarge $(\mathrm{O} 2)$ and at the secondary endpoint at 12 weeks for readmission data. The clinical and readmission data were extracted from the hospital information system. The demographic and secondary data were collected by research assistants who were trained and blind to the grouping. The inter-rater reliability reached 0.90 .

\section{Baseline demographic and clinical data}

The demographic data included age, gender, marital status, education, employment, accommodation and economic status. The clinical data included aetiology, classification, cardiac surgical intervention received, comorbidity, medications and length of stay.

\section{Primary data}

The primary data were readmissions within 4 and 12 weeks after the index hospital discharge.

\section{Secondary data}

Symptom intensity was measured by the Edmonton Symptom Assessment Scale (ESAS), which assesses eight symptoms: pain, tiredness, nausea, depression, anxiety, drowsiness, appetite, sense of well-being and dyspnoea using a $0-100 \mathrm{~mm}$ visual analogue scale with established validity and Cronbach's $\alpha$ reliability of $0.8 .^{23}$

Functional status was measured by the Palliative Performance Scale (PPS), specifically designed for palliative patients ${ }^{11}$ to reflect five physical aspects of palliative patients: ambulation, activities, self-care, intake and consciousness level. It has a rating scale from 100 (normal) to 0 (death) measured in 10\% decrements with an internal consistency Cronbach's $\alpha$ of $0.83 .^{11}$

QOL was measured by a palliative-specific scale, the McGill quality of life questionnaire-Hong Kong (MQOL-HK) version and an HF-specific scale, the chronic heart failure questionnaire-Chinese (CHQ) version. The MQOL-HK measures four domains (physical, psychological, existential and support) on a numerical scale from 0 to 10 , validated for local use with a Cronbach's $\alpha$ of $0.83 .^{24}$ The CHQ is a Canadian HF-specific QOL tool measuring 20 items on a 7-point Likert scale representing four domains: dyspnoea, fatigue, emotional status and mastery. It was translated into Chinese and validated with a Cronbach's $\alpha$ of $0.95 .^{25}$

Satisfaction with care was measured by an 11-item questionnaire validated locally with test-retest reliability of $0.87 .^{17}$

\section{Data analysis}

Statistical analysis

Descriptive statistics were presented to describe the demographic and clinical variables. Poisson regression was used to examine the mean difference in 28-day and 84-day readmission between groups, and the relative risks for the intervention group were examined. The between-group rates were compared using the $\chi^{2}$ test. The generalised estimating equation (GEE) was used to examine the group, time and interaction effects on the
Figure 1 CONSORT flow diagram of the study. CONSORT;Consolidated Standards of Reporting Trials.

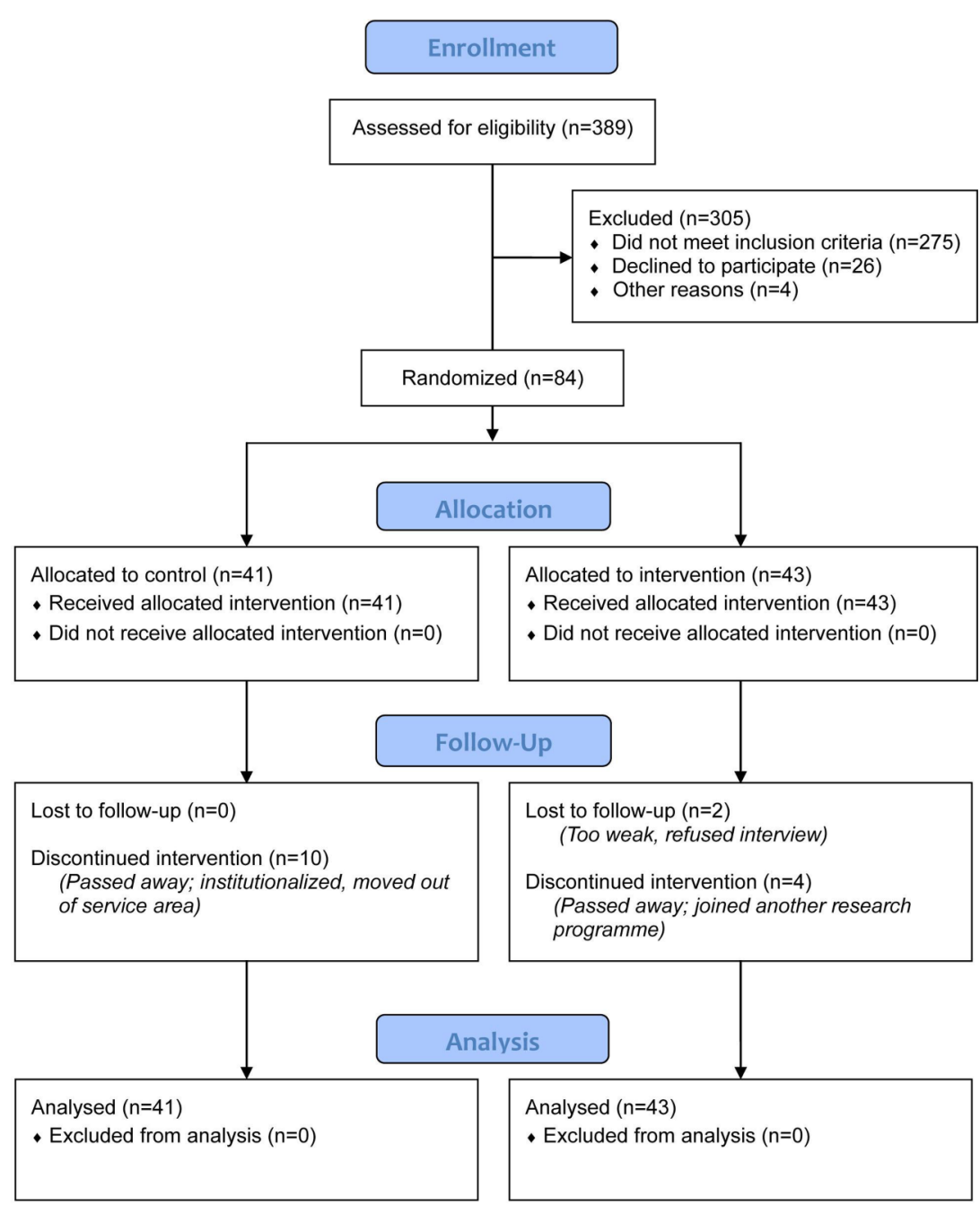


Table 1 Baseline demographic and clinical data

\begin{tabular}{|c|c|c|c|}
\hline & $\begin{array}{l}\text { Control } \\
(n=41)\end{array}$ & $\begin{array}{l}\text { Intervention } \\
(n=43)\end{array}$ & $\mathrm{p}$ Value \\
\hline Age (mean, SD) & $78.4(10.0)$ & $78.3(16.8)$ & 0.99 \\
\hline Gender & & & 0.12 \\
\hline Female & $16(39.0 \%)$ & $25(56.1 \%)$ & \\
\hline Male & $25(61.0 \%)$ & $18(43.9 \%)$ & \\
\hline Marital status & & & 0.83 \\
\hline Married & $28(68.3 \%)$ & $27(62.8 \%)$ & \\
\hline Widowed & $9(22.1 \%)$ & $13(30.2 \%)$ & \\
\hline Divorced & $2(4.8 \%)$ & $1(2.3 \%)$ & \\
\hline Single & $2(4.8 \%)$ & $2(4.7 \%)$ & \\
\hline Education & & & 0.51 \\
\hline No schooling & $12(29.3 \%)$ & $19(44.2 \%)$ & \\
\hline Primary & $20(48.8 \%)$ & $16(37.2 \%)$ & \\
\hline Secondary & $7(17.1 \%)$ & $7(16.3 \%)$ & \\
\hline University & $2(4.9 \%)$ & $1(2.3 \%)$ & \\
\hline Employment & & & 0.42 \\
\hline In employment & $1(2.4 \%)$ & $1(2.3 \%)$ & \\
\hline Retired/housewife & $40(97.6 \%)$ & $42(97.7 \%)$ & \\
\hline Household & & & 0.29 \\
\hline Living alone & $5(12.2 \%)$ & $2(4.7 \%)$ & \\
\hline Living with family & $36(87.8 \%)$ & $41(95.3 \%)$ & \\
\hline Number of family members (mean, SD) & $3(1.4)$ & $3(1.5)$ & 0.07 \\
\hline Housing type & & & 0.58 \\
\hline Rental & $5(12.2 \%)$ & $5(11.6 \%)$ & \\
\hline Private & $10(24.4 \%)$ & $14(32.6 \%)$ & \\
\hline Public/staff quarters & $26(63.4 \%)$ & $24(55.8 \%)$ & \\
\hline Perceived economic status & & & 0.74 \\
\hline More than enough & $10(24.4 \%)$ & $11(25.6 \%)$ & \\
\hline Just enough & $20(48.8 \%)$ & $25(58.1 \%)$ & \\
\hline Not enough & $11(26.8 \%)$ & $7(16.3 \%)$ & \\
\hline \multicolumn{4}{|l|}{ Chronic heart failure aetiology } \\
\hline Ischaemic heart disease & $23(56.1 \%)$ & $30(69.8 \%)$ & 0.19 \\
\hline Hypertension & $22(53.7 \%)$ & $29(67.4 \%)$ & 0.20 \\
\hline Cardiomyopathy & $4(9.8 \%)$ & $3(7.0 \%)$ & 0.65 \\
\hline Heart valve disease & $9(22.0 \%)$ & $5(11.6 \%)$ & 0.20 \\
\hline Arrhythmias & $23(56.1 \%)$ & $18(41.9 \%)$ & 0.19 \\
\hline Congenital heart defects & $1(2.4 \%)$ & $0(0)$ & 0.30 \\
\hline New York Heart Association Class & & & 0.03 \\
\hline ॥ & $3(7.3 \%)$ & $6(14.0 \%)$ & \\
\hline III & $22(53.7 \%)$ & $31(72.1 \%)$ & \\
\hline IV & $16(39.0 \%)$ & $6(14.0 \%)$ & \\
\hline Left ventricular ejection fraction (mean, SD) & $37(17)$ & $39(14)$ & 0.57 \\
\hline \multicolumn{4}{|l|}{ Cardiac surgical intervention received } \\
\hline Coronary artery bypass graft surgery & $3(7.3 \%)$ & $2(4.7 \%)$ & 0.61 \\
\hline Cardiac catheter & $15(36.6 \%)$ & $12(27.9 \%)$ & 0.39 \\
\hline Cardiac resynchronisation therapy & $4(9.8 \%)$ & $0(0)$ & 0.04 \\
\hline Implantable cardioverter defibrillator & $3(7.3 \%)$ & $1(2.3 \%)$ & 0.28 \\
\hline Percutaneous coronary intervention & $11(26.8 \%)$ & $10(23.3 \%)$ & 0.71 \\
\hline Permanent pace maker & $9(22.0 \%)$ & $2(4.7 \%)$ & 0.02 \\
\hline Valve surgery & $5(12.2 \%)$ & $4(9.3 \%)$ & 0.67 \\
\hline \multicolumn{4}{|l|}{ Comorbidity } \\
\hline Asthma & $3(7.3 \%)$ & $4(9.3 \%)$ & 0.74 \\
\hline Chronic obstructive pulmonary disease & $5(12.2 \%)$ & $2(4.7 \%)$ & 0.21 \\
\hline Cancer & $5(12.2 \%)$ & $7(16.3 \%)$ & 0.59 \\
\hline Diabetes & $15(36.6 \%)$ & $20(46.5 \%)$ & 0.36 \\
\hline Hyperlipidaemia & $9(22.0 \%)$ & $18(41.9 \%)$ & 0.051 \\
\hline Myocardial infarction & $13(31.7 \%)$ & 17 (39.5\%) & 0.45 \\
\hline Stroke & $7(17.1 \%)$ & $7(16.3 \%)$ & 0.92 \\
\hline Renal impairment & $18(43.9 \%)$ & $26(60.5 \%)$ & 0.13 \\
\hline
\end{tabular}


Table 1 Continued

\begin{tabular}{|c|c|c|c|}
\hline & $\begin{array}{l}\text { Control } \\
(n=41)\end{array}$ & $\begin{array}{l}\text { Intervention } \\
(n=43)\end{array}$ & p Value \\
\hline \multicolumn{4}{|l|}{ Medications } \\
\hline ACE inhibitors & $12(29.3 \%)$ & $17(39.5 \%)$ & 0.32 \\
\hline Anticoagulants & $9(22.0 \%)$ & $8(18.6 \%)$ & 0.70 \\
\hline Aldosterone receptor antagonists & $10(24.4 \%)$ & $10(23.3 \%)$ & 0.90 \\
\hline ARBs & $2(4.9 \%)$ & $3(7.0 \%)$ & 0.68 \\
\hline$\beta$ blockers & $13(31.7 \%)$ & $17(39.5 \%)$ & 0.45 \\
\hline Calcium channel blockers & $1(2.4 \%)$ & $6(14.0 \%)$ & 0.06 \\
\hline Digoxin & $7(17.1 \%)$ & $6(14.0 \%)$ & 0.69 \\
\hline Diuretics & $24(58.5 \%)$ & $26(60.5 \%)$ & 0.86 \\
\hline Statins & $1(2.4 \%)$ & $4(9.3 \%)$ & 0.18 \\
\hline Length of stay at index admission (median, range) & $6(1-37)$ & $5(2-66)$ & 0.93 \\
\hline \multicolumn{4}{|l|}{ PPS } \\
\hline Ambulation & $32(78.0 \%)$ & $35(81.4 \%)$ & 0.70 \\
\hline Activity & $41(100.0 \%)$ & $43(100.0 \%)$ & N/A \\
\hline Self-care & $19(46.3 \%)$ & $25(58.1 \%)$ & 0.28 \\
\hline Intake & $39(95.1 \%)$ & $43(100.0 \%)$ & 0.14 \\
\hline Conscious level & $19(46.3 \%)$ & $25(58.1 \%)$ & 0.28 \\
\hline Overall (mean, SD) & $6.6(1.2)$ & $6.4(1.0)$ & 0.55 \\
\hline \multicolumn{4}{|l|}{ ESAS } \\
\hline Pain & $21(51.2 \%)$ & $27(62.8 \%)$ & 0.28 \\
\hline Tiredness & $39(95.1 \%)$ & $42(97.7 \%)$ & 0.53 \\
\hline Nausea & $3(7.3 \%)$ & $4(9.3 \%)$ & 0.74 \\
\hline Depression & $28(68.3 \%)$ & $27(62.8 \%)$ & 0.60 \\
\hline Anxiety & $30(73.2 \%)$ & $29(67.4 \%)$ & 0.57 \\
\hline Drowsiness & $7(17.1 \%)$ & $8(18.6 \%)$ & 0.86 \\
\hline Loss of appetite & $37(90.2 \%)$ & $35(81.4 \%)$ & 0.25 \\
\hline Sense of well-being & 39 (95.1\%) & $40(93.0 \%)$ & 0.68 \\
\hline Dyspnoea & $34(82.9 \%)$ & $37(86.0 \%)$ & 0.69 \\
\hline Total & $33.0(12.7)$ & 35.5 (13.6) & 0.38 \\
\hline
\end{tabular}

ARBs, angiotensin-receptor blockers; ESAS, Edmonton Symptom Assessment Scale; PPS, Palliative Performance Scale.

secondary outcome variables. GEE was used because it treats observations of longitudinal data as correlated, using robust SE estimates to get valid inference. ${ }^{26}$ The proportion of patients with improvement/deterioration/no change in symptoms (ESAS) was calculated based on the minimal clinically important difference (MCID) cut-off reported in studies by Hui et al,,$^{28}$ and differences across groups were examined using $\chi^{2}$ tests. Both readmissions and MCID were computed based on actual data. The principle of intention to treat was employed and all statistical analyses were conducted using SPSS V.22.0 for Windows.

\section{RESULTS}

A total of 389 subjects were screened, with 305 excluded. The remaining 84 eligible subjects were randomised. A total of 16 subjects were lost to follow-up (see figure 1). Table 1 displays the demographic and clinical baseline data. The mean age of the subjects was 78.3 , with males (52.4\%) slightly outnumbering females. The demographic background of the two groups was equivalent. There was no significant between-group difference in clinical parameters, including HF aetiology, mean left ventricular ejection fraction, comorbidity, treatment and

Table 2 Readmission at 4 and 12 weeks

\begin{tabular}{|c|c|c|c|}
\hline & $\begin{array}{l}\text { Control } \\
(n=41)\end{array}$ & $\begin{array}{l}\text { Intervention } \\
(n=43)\end{array}$ & p Value \\
\hline Number of readmissions at 4 weeks (mean, SE) & $0.41(0.10)$ & $0.21(0.07)$ & 0.10 \\
\hline Number of readmissions at 12 weeks (mean, SE) ${ }^{* *}$ & $1.10(0.16)$ & $0.42(0.10)$ & 0.001 \\
\hline \multicolumn{4}{|l|}{ Readmissions within 28 days (n, \%) } \\
\hline No & $29(70.7 \%)$ & $34(79.1 \%)$ & 0.38 \\
\hline Yes & $12(29.3 \%)$ & $9(20.9 \%)$ & \\
\hline \multicolumn{4}{|l|}{ Readmissions within 84 days $(n, \%)^{*}$} \\
\hline No & $16(39.0 \%)$ & $29(67.4 \%)$ & 0.009 \\
\hline Yes & $25(61.0 \%)$ & $14(33.6 \%)$ & \\
\hline
\end{tabular}


Table 3 Change in ESAS at $02(n=68)$

\begin{tabular}{|c|c|c|c|c|c|c|}
\hline & \multirow[b]{2}{*}{ Deterioration } & \multicolumn{3}{|c|}{ Control $(n=31)$} & \multicolumn{2}{|c|}{ Intervention $(\mathrm{n}=37)$} \\
\hline & & No change & Improvement & Deterioration & No change & Improvement \\
\hline \multicolumn{7}{|l|}{ Frequency (\%) } \\
\hline Pain & $10(32.3 \%)$ & $11(35.5 \%)$ & $10(32.3 \%)$ & $8(21.6 \%)$ & $15(40.5 \%)$ & $14(37.8 \%)$ \\
\hline Tiredness & $11(35.5 \%)$ & $10(32.3 \%)$ & $10(32.3 \%)$ & $7(18.9 \%)$ & $13(35.1 \%)$ & $17(45.9 \%)$ \\
\hline Nausea & $1(3.2 \%)$ & $30(96.8 \%)$ & $0(0.0 \%)$ & $1(2.7 \%)$ & $34(91.9 \%)$ & $2(5.4 \%)$ \\
\hline Depression* & $11(35.5 \%)$ & $15(48.4 \%)$ & $5(16.1 \%)$ & $7(18.9 \%)$ & $13(35.1 \%)$ & $17(45.9 \%)$ \\
\hline Anxiety & $8(25.8 \%)$ & $16(51.6 \%)$ & $7(22.6 \%)$ & $8(21.6 \%)$ & $13(35.1 \%)$ & $16(43.2 \%)$ \\
\hline Drowsiness & $3(9.7 \%)$ & $25(80.6 \%)$ & $3(9.7 \%)$ & $1(2.7 \%)$ & 31 (83.8\%) & $5(13.5 \%)$ \\
\hline Loss of appetite & $10(32.3 \%)$ & $9(29.0 \%)$ & $12(38.7 \%)$ & $7(18.9 \%)$ & $16(43.2 \%)$ & $14(37.8 \%)$ \\
\hline Sense of well-being & $14(45.2 \%)$ & $10(32.3 \%)$ & $7(22.6 \%)$ & $14(37.8 \%)$ & $9(24.3 \%)$ & $14(37.8 \%)$ \\
\hline Dyspnoea* & $10(32.3 \%)$ & $12(38.7 \%)$ & $9(29.0 \%)$ & $7(18.9 \%)$ & $7(18.9 \%)$ & $23(62.2 \%)$ \\
\hline Total $^{*}$ & $12(41.4 \%)$ & $5(17.2 \%)$ & $12(41.4 \%)$ & $7(18.9 \%)$ & $3(8.1 \%)$ & $27(73.0 \%)$ \\
\hline
\end{tabular}

medications received, except for the NYHA Class $(p=0.03)$. The perceived health status (PPS and ESAS) at baseline were equivalent in the two groups, and there was no significant difference in their length of hospital stay.

The intervention group had a lower 4-week readmission rate (intervention $20.9 \%$ vs control $29.3 \% \chi^{2}=4.41, p=0.79$ ) and mean number of readmissions (intervention 0.21 (SE 0.07) vs control 0.41 (SE 0.10) $\mathrm{p}=0.097$ ), but the difference was not significant. At 12 weeks, the readmission rate (intervention 33.6\% vs control $\left.61.0 \% \chi^{2}=6.8, p=0.009\right)$ and mean number of readmissions (intervention 0.42 (SE 0.10) vs control 1.10 (SE 0.16), $\mathrm{p}=0.001$ ) became significantly lower for the intervention group (see table 2). The relative risks (CI) for 4-week and 12-week readmissions for the intervention group were, respectively, 0.81 (0.51 to 1.27$)$ and 0.55 (0.35 to 0.88$)$.

The MCID of the symptom intensity was examined. Compared with the control group, the intervention group experienced significantly higher clinical improvement in depression $(45.9 \%$ vs $16.1 \%, \mathrm{p}<0.05)$, dyspnoea $(62.2 \%$ vs $29.0 \%$, $\mathrm{p}<0.05)$ and total score $(73.0 \%$ vs $41.4 \%, \mathrm{p}<0.05)$ (table 3$)$.

Table 4 displays the results of the secondary outcome comparing the baseline and week 4 . There was no difference in functional status (PPS) within or between groups over time. There was some improvement in the symptom intensity of depression and anxiety as measured by ESAS over time in the intervention group, but there was no difference in improvement between groups. Both measures of QOL, the Chronic heart-failure questionnaire Chinese (CHQC) $(\mathrm{p}<0.01)$ and McGill QOL $(p<0.05)$, showed a significant difference in the change over time between groups. When individual items were examined, all achieved statistically significant difference with group-time effect, except for 'fatigue' in CHQC and 'physical' and 'existential' in McGill. The intervention group had significantly higher satisfaction with care than the control group $(\mathrm{p}<0.001)$.

\section{DISCUSSION}

This study adds to the evidence that an intensive 4-week transitional home-based programme sustained by monthly follow-up is effective in reducing readmissions, controlling symptoms and enhancing QOL among patients with ESHF on returning home after hospital discharge.
The design of the TCP-ESHF programme in this study contained evidence-based elements identified by a current systematic review that were found to be effective in reducing hospital readmissions. They were the use of multicomponents in interventions involving a multidisciplinary team in care delivery and supporting clients to optimise capacity for self-care. ${ }^{29}$ Few transitional care studies have been conducted among patients with ESHF. Brumley et al tested a palliative programme among noncancer patients, including HF and COPD subjects, finding that an in-home PC group had higher satisfaction and fewer hospitalisations than a usual care group. ${ }^{11}$ This study obtained the same results and was also consistent with other trials in demonstrating that a home-based PC programme could enhance QOL. ${ }^{112}$ As in other studies, ${ }^{19}$ dyspnoea and fatigue were two common symptoms reported by subjects in this study. The NCMs in this study were able to empower their patients in symptom management, make adjustments to medications and offer early referral if appropriate. ${ }^{11} 18$ Previous studies that examined the effects of palliative home-based support focused on patients in the community who were referred for home care. ${ }^{1120}$ This study shows that transitional care support after an episode of hospitalisation enabled patients to reduce hospital use and stay well in the community. Similar transitional care programmes, led by professionals and supported by volunteers, have proved cost-effective among general medical patients. ${ }^{30}$

Patients with ESHF have typical PC needs that include symptom control and psychosocial support. ${ }^{31}$ The use of PC among patients with $\mathrm{HF}$ is low, ${ }^{9}$ as reflected by the low statistics that ranged from only $5 \%$ for non-cancer ${ }^{10}$ to $12 \%$ for $\mathrm{HF}^{32}$ users of hospice services. One of the challenges in referring patients with HF to PC services is the unpredictable illness trajectory of $\mathrm{HF}$, which makes accurate prognostication difficult. ${ }^{33}$ Advocacy of the PC approach in HF treatment guidelines helps remind clinicians to adopt this approach when appropriate and in the best interests of patients. ${ }^{32}$ The triggering of the palliative approach needs the collaboration of both PC and medical specialists. ${ }^{9}$ This study benefited from explicit referral guidelines developed in the study sites, supported by the medical/cardiac team and hospital management.

Stuart asserts that the alignment of financial incentives between specialties and across healthcare settings is important, particularly when the provision of care needs to extend from 
Table 4 Secondary outcomes at 01 and 02

\begin{tabular}{|c|c|c|c|c|}
\hline & \multicolumn{2}{|c|}{ Control $(n=41)$} & \multicolumn{2}{|c|}{ Intervention $(n=43)$} \\
\hline & 01 & 02 & 01 & 02 \\
\hline \multicolumn{5}{|l|}{ Palliative performance scale $(\%, \mathrm{SE})$} \\
\hline Ambulation & $79.6(25.2)$ & $69.2(33.4)$ & $82.2(22.7)$ & $76.0(28.4)$ \\
\hline Activity & $100.0(0.0)$ & $100.0(0.0)$ & $100.0(0.0)$ & $100.0(0.0)$ \\
\hline Self-care & $45.6(44.1)$ & $30.8(38.1)$ & $59.8(42.7)$ & $40.5(42.9)$ \\
\hline Intake & $90.0(6.0)$ & $91.9(5.2)$ & $91.9(4.9)$ & $89.8(6.2)$ \\
\hline Conscious level & $45.6(44.1)$ & $30.8(38.1)$ & $59.8(42.7)$ & $40.5(42.9)$ \\
\hline Overall & $65.5(18.0)$ & $66.8(18.9)$ & $64.72(15.13)$ & $66.85(18.67)$ \\
\hline \multicolumn{5}{|c|}{ Edmonton Symptom Assessment System (\%, SE) } \\
\hline Pain & $51.5(44.6)$ & $42.0(43.9)$ & $63.1(40.6)$ & $56.4(44.0)$ \\
\hline Tiredness & $90.0(7.0)$ & $91.6(6.9)$ & $91.0(6.3)$ & $89.8(7.2)$ \\
\hline Nausea & $11.1(9.4)$ & $10.8(9.4)$ & $12.1(10.1)$ & $9.1(7.9)$ \\
\hline Depression & $70.9(35.5)$ & $58.0(42.2)$ & $65.1(39.0)$ & $36.4(33.5)^{* *}$ \\
\hline Anxiety & 75.5 (31.6) & $50.0(43.1)$ & $70.0(35.9)$ & $34.5(38.8)^{\star *}$ \\
\hline Drowsiness & $16.8(17.2)$ & $14.4(15.4)$ & $17.8(18.0)$ & $9.1(10.2)$ \\
\hline Loss of appetite & $87.6(15.9)$ & $75.7(27.4)$ & $82.2(21.5)$ & $68.3(31.9)$ \\
\hline Sense of well-being & $90.0(9.2)$ & $89.2(10.0)$ & $89.0(9.9)$ & $85.7(12.5)$ \\
\hline Dyspnoea & $83.2(20.3)$ & $81.1(22.5)$ & $85.2(18.3)$ & $71.0(30.0)$ \\
\hline Total & $35.13(2.15)$ & 32.39 (3.20) & $33.32(1.93)$ & $23.97(2.20)^{* * *}$ \\
\hline \multicolumn{5}{|c|}{ Chronic Heart Failure Questionnaire (score, SE) } \\
\hline Dyspnoea** $^{*}$ & $4.83(0.18)$ & $4.89(0.28)$ & $4.65(0.17)$ & $5.82(0.19)^{\star * \star}$ \\
\hline Fatigue & $3.64(0.20)$ & $3.77(0.24)$ & $3.80(0.20)$ & $4.19(0.26)$ \\
\hline Emotional** & $4.86(0.24)$ & $4.61(0.29)$ & $5.09(0.19)$ & $5.68(0.17)^{* *}$ \\
\hline Mastery** & $4.58(0.22)$ & $4.64(0.26)$ & $4.30(0.22)$ & $5.36(0.22)^{* * *}$ \\
\hline Total** & $4.49(0.15)$ & $4.47(0.23)$ & $4.45(0.14)$ & $5.26(0.17)^{\star * *}$ \\
\hline \multicolumn{5}{|c|}{ McGill Quality of Life Questionnaire (score, SE) } \\
\hline Physical & $4.07(0.25)$ & $4.79(0.33)^{*}$ & $4.48(0.25)$ & $5.72(0.35)^{* * *}$ \\
\hline Psychological* & $7.63(0.33)$ & $7.71(0.48)$ & $7.82(0.30)$ & $9.06(0.23)^{* * *}$ \\
\hline Existential & $5.61(0.45)$ & $5.86(0.50)$ & $6.01(0.38)$ & $7.17(0.35)^{* *}$ \\
\hline Support* & $8.05(0.30)$ & $7.82(0.39)$ & $7.87(0.32)$ & $8.57(0.25)^{*}$ \\
\hline Overall* & $6.33(0.33)$ & $6.16(0.44)$ & $6.41(0.32)$ & $7.37(0.29)^{*}$ \\
\hline Total* & $6.35(0.23)$ & $6.46(0.36)$ & $6.51(0.22)$ & $7.57(0.21)^{* * *}$ \\
\hline Satisfaction with care $(\text { score, } \mathrm{SE})^{* * *}$ & $\mathrm{~N} / \mathrm{A}$ & $36.55(2.09)$ & N/A & $48.84(1.82)$ \\
\hline
\end{tabular}

hospital to home. ${ }^{32}$ Having an innovative infrastructure design is important in helping to integrate the PC approach into the continuum of HF care. ${ }^{4}$ The design of the TCP-ESHF achieved the delivery of services that were comprehensive and coordinated in collaboration with a team comprising professionals and volunteers supporting patients with continuity. When the biomedical curative approach of adding years to life is no longer possible, the holistic approach of PC to control symptoms and address patients' needs is a preferred alternative. ${ }^{4}$

This study has a number of limitations. The loss of follow-up was high, which is not uncommon among palliative patients. The rate was $24.4 \%$ and $14.0 \%$, respectively, for the control and intervention groups, the main reasons being death and deterioration. The sample size was relatively small and there was a significantly higher NYHA class in the control compared with the intervention group. The study was conducted in Hong Kong, whose healthcare system differs from those in other countries. Repeated studies should be conducted both within and outside Hong Kong with larger sample sizes to confirm the internal and external validity of the findings. This study has focused on administrative outcomes, namely hospital readmissions. No existing studies have reported MCID for QOL, which is an important outcome measure for palliative patients. This study used symptom measures to calculate MCID, which fails to reflect the clinically important overall well-being of the patients.

\section{CONCLUSIONS}

This study has provided evidence of the effects of a postdischarge home-based palliative programme in reducing readmissions and enhancing QOL among patients with ESHF. The shifting of the focus from treatment to symptom control in the continuum of care requires the support of both cardiologists and PC physicians in building a referral mechanism and service model in the delivery of care. Home care nurses who are experienced in PC as well as HF symptom management are instrumental in providing continuity of care for patients immediately after hospital discharge. The nurse's access to both physician and multidisciplinary team is essential in providing early intervention when problems are detected. 


\section{Key messages}

What is already known on this subject?

- Palliative care enhances quality at the end of life among patients with cancer.

- Transitional care support after hospital discharge reduces readmissions and enhances clients' quality of life.

\section{What might this study add?}

- Specialist palliative care is beneficial to non-cancer patients who are at the end-stage of organ failure.

- Transitional care support, led by professionals supported by volunteers, can reduce hospital readmissions, enhance quality of life and achieve significantly higher clinical improvement in symptom control among patients with end-stage heart failure.

\section{How might this impact on clinical practice?}

- Patients with heart failure at an advanced stage and refractory to medical therapy would benefit from specialist palliative care.

- The deliberate design of transitional care support for patients with end-stage heart failure requires organisational support to develop clear referral guidelines between medical and palliative care physicians, and mobilising resources to ensure continuity of care extended from hospital to home.

Acknowledgements We would like to acknowledge the support of the nurse case managers in delivering the interventions. They are Ka-mei Chan from Grantham Hospital, Tsan-yu Chan, Ka-chi Lau from Haven of Hope Hospital and Yuk-ying Tsang from United Christian Hospital. We are also indebted to Dr John E Sanderson, Clinical Professor in the Department of Medicine and Therapeutics at the Chinese University of Hong Kong to help critically review the draft manuscript. The work described in this paper was fully supported by a grant from the Research Grants Council of the Hong Kong Special Administrative Region, China (RGC Ref No 549212).

Contributors The listed authors all have contributed substantially to the research and manuscript. The leading author, FKYW, is responsible for the conception and design of the study, data interpretation, composing the draft manuscript and overall quality of the work. The second author, AYMN, is responsible for data collection and data interpretation. The third author, PHL, is responsible for data analysis and data interpretation. The fourth to seventh authors are on the clinical team, providing valuable comments on the feasibility of the study, supporting the recruitment of subjects, reviewing clinical data and make interpretations. All authors have provided critical comments to the manuscript resulting in a number of revisions in the process and they have all approved the final version. The entire team is accountable to all aspects of the work and hold high standards in safeguarding the accuracy and integrity of the investigation.

Funding The work described in this paper was fully supported by a grant from the Research Grants Council of the Hong Kong Special Administrative Region, China (RGC Ref No 549212).

Competing interests None declared.

Ethics approval Human Subjects Ethics Sub-Committee of the Hong Kong Polytechnic University and Institutional Review Board of Hospital Authority, Hong Kong West Cluster and Kowloon Central/Kowloon East Cluster.

Provenance and peer review Not commissioned; externally peer reviewed.

Data sharing statement This study only reported data up to 4-12 weeks after the baseline. The entire data collection is up to 12 months, including quality of life, symptom and healthcare usage data. The research team is willing to share with researchers conducting similar studies. Interested parties can approach the research team directly.

Open Access This is an Open Access article distributed in accordance with the Creative Commons Attribution Non Commercial (CC BY-NC 4.0) license, which permits others to distribute, remix, adapt, build upon this work non-commercially, and license their derivative works on different terms, provided the original work is properly cited and the use is non-commercial. See: http://creativecommons.org/ licenses/by-nc/4.0/

\section{REFERENCES}

1 Adler ED, Goldfinger JZ, Kalman J, et al. Palliative care in the treatment of advanced heart failure. Circulation 2009;120:2597-606.

2 Gadoud A, Jenkins SMM, Hogg KJ. Palliative care for people with heart failure: summary of current evidence and future direction. Palliat Med 2013;27:822-8.

3 Blinderman CD, Homel P, Billings JA, et al. Symptom distress and quality of life in patients with advanced congestive heart failure. J Pain Symptom Manage 2008;35:594-603.

4 Selman L, Harding R, Beynon T, et al. Modelling services to meet the palliative care needs of chronic heart failure patients and their families: current practice in the UK. Palliat Med 2007;21:385-90.

5 Hunt SA, Abraham WT, Chin MH, et al. 2009 focused update incorporated into the ACC/AHA 2005 guidelines for the diagnosis and management of heart failure in adults a report of the American College of Cardiology Foundation/American Heart Association Task Force on Practice Guidelines developed in collaboration with the International Society for heart and lung transplantation. J Am Coll Cardiol 2009;53: e1-90.

6 Horne G, Payne S. Removing the boundaries: palliative care for patients with heart failure. Palliat Med 2004;18:291-6.

7 Johnson JO, Sulmasy DP, Nolan MT. Patients' experience of being a burden on family in terminal illness. J Hosp Palliat Nurs 2007;9:264-9.

8 Quill TE, Abernethy AP. Generalist plus specialist palliative care-creating a more sustainable model. N Engl J Med 2013;368:1173-5

9 O'Leary N. The comparative palliative care needs of those with heart failure and cancer patients. Curr Opin Support Palliat Care 2009;3:241-6.

10 Gibbs LME, Khatri AK, Gibbs JSR. Survey of specialist palliative care and heart failure: September 2004. Palliat Med 2006;20:603-9.

11 Brumley RD, Enguidanos S, Cherin DA. Effectiveness of a home-based palliative care program for end-of-life. J Palliat Med 2003;6:715-24.

12 Kavalieratos D, Mitchell EM, Carey TS, et al. "Not the "grim reaper service'": an assessment of provider knowledge, attitudes, and perceptions regarding palliative care referral barriers in heart failure. J Am Heart Assoc 2014;3:e000544.

13 Lorenz KA, Lynn J, Dy SM, et al. Evidence for improving palliative care at the end of life: a systematic review. Ann Intern Med 2008;148:147-59.

14 Jeon $\mathrm{YH}$, Kraus SG, Jowsey $\mathrm{T}$, et al. The experience of living with chronic heart failure: a narrative review of qualitative studies. BMC Health Serv Res 2010;10:77.

15 Enguidanos S, Portanova J. The provision of home-based palliative care for those with advanced heart failure. Curr Opin Support Palliat Care 2014;8:4-8.

16 Evangelista LS, Liao S, Motie $M$, et al. On-going palliative care enhances perceived control and patient activation and reduces symptom distress in patients with symptomatic heart failure: a pilot study. Eur J Cardiovasc Nurs 2014;13:116-23.

17 Wong FKY, Ho MM, Yeung SY, et al. Effects of a health-social partnership transitional program on hospital readmission: a randomized controlled trial. Soc Sci Med 2011;73:960-9.

18 Wong FK, Chow SK, Chan TM, et al. Comparison of effects between home visits with telephone calls and telephone calls only for transitional discharge support: a randomized controlled trial. Age Ageing 2014;43:91-7.

19 National Gold Standards Framework Centre. Prognostic Indicator Guidance. 2008 http://www.goldstandardsframework.org.uk/Resources/Gold\%20Standards\% 20Framework/PDF\%20Documents/PrognosticIndicatorGuidancePaper.pdf (accessed 8 Sept 2011).

20 Lukas L, Foltz C, Paxton H. Hospital outcomes for a home-based palliative medicine consulting service. J Palliat Med 2013;16:179-84.

21 Lehr R. Sixteen S-squared over D-squared: a relation for crude sample size estimates. Stat Med 1992;11:1099-102.

22 Jaarsma T, Beattie JM, Ryder $M$, et al. Palliative care in heart failure: a position statement from the palliative care workshop of the Heart Failure Association of the European Society of Cardiology. Eur J Heart Fail 2009;11:433-43.

23 Bakitas M, Lyons KD, Hegel MT, et al. Effects of a palliative care intervention on clinical outcomes in patients with advanced cancer: the project ENABLE ॥ randomized controlled trial. JAMA 2009:302:741-9.

24 Lo RS, Woo J, Zhoc KC, et al. Cross-cultural validation of the McGill quality of life questionnaire in Hong Kong Chinese. Palliat Med 2001;15:387-97.

25 Lee DT, Yu DS, Woo J. Validation of the Chronic Heart Failure Questionnaire (Chinese version). Qual Life Res 2005;14:1421-6.

26 Hanley JA, Negassa A, Edwardes MD, et al. Statistical analysis of correlated data using generalized estimating equations: an orientation. Am J Epidemiol 2003;157:364-75.

27 Hui D, Shamieh O, Paiva CE, et al. Minimal clinically important differences in the Edmonton Symptom Assessment Scale in cancer patients: a prospective, multicenter study. Cancer 2015;121:3027-35. 
28 Hui D, Shamieh O, Paiva $C E$, et al. Minimal clinically important differences in the physical, emotional, and total symptom distress scores of the Edmonton Symptom Assessment System. J Pain Symptom Manage 2016;51:262-69.

29 Leppin AL, Gionfriddo MR, Kessler M, et al. Preventing 30-day hospital readmissions: a systematic review and meta-analysis of randomized trials. JAMA Intern Med 2014;174:1095-107.

30 Wong FKY, Chau J, So C, et al. Cost-effectiveness of a health-social partnership transitional program for post-discharge medical patients. BMC Health Serv Res 2012;12:479.
31 Dev S, Abernethy AP, Rogers JG, et al. Preferences of people with advanced heart failure-a structured narrative literature review to inform decision making in the palliative care setting. Am Heart J 2012;164: 313-319.e5.

32 Stuart $B$. The nature of heart failure as a challenge to the integration of palliative care services. Curr Opin Support Palliat Care 2007;1:249-54.

33 Brunner-La Rocca HP, Rickenbacher P, Muzzarelli S, et al. End-of-life preferences of elderly patients with chronic heart failure. Eur Heart J 2012;33:752-9. 